\title{
Integrating Digital Technology in the School Curriculum
}

\author{
https://doi.org/10.3991/ijet.v14i21.10863 \\ João Filipe Matos, Ana Pedro ${ }^{(凶)}$, João Piedade \\ University of Lisbon, lisbon, Portugal \\ aipedro@ie.ulisboa.pt
}

\begin{abstract}
This article aims to challenge and interrogate the concept of integration of digital technology in the curriculum. We set the stage for the discussion taking the notion of curriculum and discussing the way teachers take it as a mediating tool and structuring resource for teaching. In the next step we engage in the discussion of learning as transformative participation in school social practices and locate digital technology within that problematic situation. We then go into the key claim of the article arguing for the myth of integration of digital technology in the curriculum. This provides the background for formulating a set of principles that would support the development of a framework for digital technology in education and respective contextual guidelines. To conclude we provide examples of topics under-represented in the research that are crucial to support such a framework.
\end{abstract}

Keywords-Learning, curriculum, innovation, digital technology, students and teachers' practice

\section{$1 \quad$ Introduction}

In education, internal and external forces lead to ever-changing scenarios in classrooms. New understandings of how children learn outside the school and in formal school settings as well as dynamic changes in curriculum and digital technology, result in the need for pedagogic retooling. In addition, population shifts within and between nations produce different educational needs for children in classrooms. Those forces combined with a revision of our understanding of what constitutes learning, call for a discussion on how the issue of using technology in education is being addressed and researched. The general concern of educators and teachers (and even of educational authorities around the world) with the question of 'integration of digital technology in the curriculum' is well known. As we will argue in this article, this concern is visible at the level of research reported and at the curriculum guidelines in several countries.

\section{On The Curriculum}

Despite the existing variety of computational subcultures (e.g. web video gaming, youtubing and social network activities, the vision of an acceptable computer culture 
at school has not been established yet, at least from a progressive educational point of view. But we all know many examples (although fragmented in their school communities) in which children with dedicated teachers and intellectually stimulating digital technology applications are creating pieces for a new educational reality.

The way teachers appropriate the curriculum are central to the discussion of its place in the educational system. But the issue goes a step back as the need for policymakers and educators to adapt educational curricula to changing labor markets is a worldwide concern. For example, [1] stresses the importance of technical and professional skills as well as generic digital technology skills needed to understand, use and adopt technologies. In parallel, life-learning ability to adapt to technology changes and creativity, communication skills, critical and logical thinking, teamwork and digital entrepreneurship are pointed out as complementary digital technology soft skills categorized as future work skills (p. 3). Likewise, research centered on competency analysis shows what we mean when we refer to technological competencies [2].

Traditionally, the teaching curriculum offers a path that the teacher should follow (regardless of the topic or discipline in question) to achieve predefined goals. In fact, the discourse that schools propose to teachers (and frequently impose on them) suggest styles and forms of practice that are supposed to be the most efficient for curricular purposes. That discourse offers a rationale to make sense, to justify, to legitimate and to explain teachers' practices to students and parents. According to [3], this is the field of reproduction of knowledge where in fact knowledge is re-contextualized as part of the pedagogical plan. The curriculum is the referent of that pedagogical plan. Teachers act within the field of reproduction of knowledge - the secondary context as [3] calls it. This is where the selective reproduction of the educational discourse takes place and includes agencies and practices at different levels (from kindergarten to higher education) as well as interrelations between those levels.

The pedagogical discourses created in the field of re-contextualization (traditionally structured by the curriculum and the textbooks) are again transformed according to each teacher's appropriation of said discourses. In this process, the original discourse suffers an ideological transformation according to interests within the recontextualization field (i.e. the schools, the teachers). When pedagogical discourses (produced within the field of official discourse) are introduced in a classroom, they go through a process of re-contextualization that depends on the specific educational options of the school, the teachers and the community (including parents). Therefore, the discourse produced in classroom is a result of the relationships that make the specific contexts of teaching (where the school and the community are included).

This discussion shows the complexity of school practices and teachers' tasks and legitimates the claim that the curriculum is a structuring resource, often used by teachers as an artefact. The curriculum should be viewed within the framework of the social world where it is constructed and used. We must consider the mediating and symbolic character of the curriculum as an artefact as emphasized by socio-historical theorists (e.g. [4]) and recognized by situated learning perspectives (e.g. [5]).

In this brief discussion of the curriculum's role in school practices, we take the structure of an activity system's model, as proposed by [4], and we concentrate on one of its elements - the artefacts in relation to other elements. We will then look at the 
links between the notion of curriculum (as artefact) and the idea of mediation. It is common to see people distinguishing artefacts in two ways - on one hand, people refer to tools and signs, and on the other hand, we find researchers considering external (or practical) artefacts and internal (or cognitive) artefacts. We should notice that in both approaches. The internal character of the artefacts is what determines its classification, independently of which it is used in.

In any activity, functions and uses of artefacts are in constant transformation. Therefore, elements that seem to be internal in certain moment are externalized (for example through speech) as much as the external processes in certain occasions can be internalized. Freezing or splitting these processes seems to be an insufficient basis artefact understanding [4]. The author proposes a differentiation regarding the uses of artefacts that helps understanding the place of the curriculum in school:

"The first type is what artefacts used to identify and describe objects. The second type is how artefacts used to guide and direct processes and procedures on, within or between objects. The third type is why artefacts used to diagnose and explain the properties and behavior of objects. Finally the fourth type is where to artefacts used to envision the future state or potential development of objects including institutions and social systems." [6] (Italics in the original, p. 382)

This categorization of artefacts highlights that they are not being considered by themselves but always in relation to a certain use and inserted in a system of activity. Following Engeström's perspective [6], the school practice, mediated by the curriculum as an artefact, is a collaborative and dialectic process in its core and where different perspectives and voices meet, collide and mix. This makes the complexity of the teacher's task in dealing with prescriptive curriculum guidelines more visible. These guidelines may not draw from the collective essence of education activity, potentially creating inner conflicts in teachers' pedagogical options.

The claim just presented is a rather strong challenge to curriculum designers and educational authorities and even a greater challenge to the idea of 'introducing digital technology in the curriculum'. Attention should be drawn to the diversity of meanings which are produced by the idea of 'digital technology in education' as meanings impinge on each other; in school, for example, there are multiple meanings stemming from the idea of 'teaching digital technology', 'teaching with digital technology', etc. All of those notions share an emphasis on 'teaching' and on the need to have a curriculum stating what students should learn or what are teachers' perspectives to enhance learning in classroom [7]. Although we welcome and celebrate the diversity in interpretation of what is relevant in the use of digital technology in education, we identify a strong tendency to center attention in the curriculum and consequently, creating the problem of 'delivering digital technology in education' or 'introducing digital technology in the curriculum'.

\section{On Learning and Digital Technologies}

In 2001, when [8] the author stated that "students have changed radically, today's students are no longer the people our educational system was designed to teach", he 
brought into discussion the need to think how students learn in a dynamic and changing social context and how schools should deal with new generation of students. While [8] suggested a distinction between natives and immigrants, he [8]; [9] made it explicit that 'natives' are being taught by 'immigrants' who are, in effect, not talking the same language nor living within the same system of activity.

For a number of years, the discussion on natives versus immigrants was part of academic work (with different perspectives) but we must situate that discussion in its time. The author referred to the first generation of students born in a technology-rich social world interacting rather naturally with it, as he introduced an opposition between 'natives' and 'immigrants'. "As Digital Immigrants learn - like all immigrants, some better than others - to adapt to their environment, they always retain, to some degree, their "accent," that is, their foot in the past. The "digital immigrant accent" can be seen in such things as turning to the Internet for information second rather than first, or in reading the manual for a program rather than assuming that the program itself will teach us how to use it (p.2)" [8].

If students have access to computers, touchpads, mobile technology, videogames, digital music players and all the variety of 'toys' and tools of the digital age, their needs as students are certainly different from ten years ago and this should impact curriculum guidelines. Processes of using information - search, selection, accommodation and assimilation - are critically different [10]; [11] should be treated as different by the school and the curriculum [11].

Therefore, teachers need to establish forms of communication "in a way that fits with the needs of the digital natives i.e. going faster, less step-by step, more in parallel with more random access among other things (p.2)" [8]. As stated by Tapscott, (2009, cit. by [12]), the new generations are imposing a change in pedagogy models from a teacher-focused approach based on instruction to a student-focused model based on collaboration.

The so called 'gap' existing between practices of students in school and outside school is well known and in some sense, this also applies to teachers. Still, we need to look at gaps in social practices as a mere point of view if we admit that there is continuity in everyday practices. Rules applied in schooling are much clearer and explicit in fact, rules are reified in the curriculum and in school organization and translate to classes, exams, etc. - then in other social spaces, outside school. We should note that everyday practices (where we include schooling, as is the place where students spend most of their time) are 'ruled' by scripts that in many cases constitute a kind of curriculum one should learn to perform in socially adequate forms. So, the idea of bridging the gap between schooling and home practices must be unpacked, concentrating the effort on the artifacts (instruments, tools, rules) that make the different systems of activity in order to create real gaps that contribute to the emergence of discontinuities in practices. It is therefore important to identify the factors and strategies that can help enhancing the use of digital technology in school and bridging the gap between schooling and other aspects of students' lives. 


\section{The myth of Digital Technology Integration in the Curriculum}

The efforts for integrating digital technology within the school curriculum derive from the mythical idea that 'students will learn what is in the curriculum'. In fact (and perhaps unfortunately) this is not the case. Educational authorities' belief in the 'myth of the curriculum': the idea is that, once clearly stated in the curriculum and in textbooks, learning objectives and contents become objects that are easy to learn or teach. This utilitarian view of the curriculum is often adopted by teachers while planning lessons and it becomes one of the many existing school myths.

Myths play a major role in people's lives. They help organize experiences even when they don't portray real problems or solutions. People often take myths to support and legitimate actions and decisions. However, as teachers or educators we must question and deconstruct myths inherent to schooling. The myth of the curriculum as driving force for learning is well established in teaching. In fact, objectives, contents and teaching methods that constitute the curriculum documents are mere reifications of teaching practices that shouldn't be taken as the source of learning.

Most myths about the integration of digital technology in the curriculum results from un-problematized and oversimplified visions of digital technology in schooling of its forms and application strategies (e.g. for assessment and accountability purposes) and from the de-problematization of its use at large in society. In contrast, students bring meanings and practices from outside school which are diverse, powerful and one step ahead of the schools' view of digital technology in society (and generally of their teachers' perspectives). Those two rather different mindsets — the school-rulesbased perspective and the extra-school everyday context perspective - stand in tension with each other and tend not to feed each other but to radicalize and get closed in their own boxes.

A key element that should contribute to manage that tension is the way teachers use the school curriculum as a mediating artefact in their teaching practices. An open view of the role of digital technology in school requires teachers to address what happens in larger structures inside the social organization of the school. Teachers as curriculum developers would bring them to operate inside their professional community, seeing themselves as a transforming agent [13].

In 1980, [14] wrote in his book Mindstorms:

- $\quad$ If, as I have stressed here, the model of successful learning (i.e. Piaget etc.) is the way a child learns to talk, a process that takes place without deliberate and organized teaching, the goal set is very different. I see the classroom as an artificial and inefficient learning environment that society has been forced to invent because its informal environments fail in certain essential learning domains, such as writing or grammar or school mathematics. I believe that the computer presence will enable us to so modify the learning environment outside the classroom that much if not all the knowledge schools presently try to teach with such pain and ex- 
pense and such limited success will be learnt as the child learns to talk painlessly, successfully and without organized instruction. (p.8) [14]

Even if it still seems quite radical, after 40 years, this quote suggests a reflection on how schools are still nowadays addressing the promotion of digital technology application in learning. It is a fact that the social world impoverished in certain kinds of learning (e.g. mathematics) -kinds of learning that schools traditionally imposed on children for 200 years. Still, everybody recognizes that digital technology is transforming the way people deal with knowledge in many activity domains and even the way they deal with their everyday problems and situations [15], [16].

Digital technology powerfully enabled the contexts of practice outside the classroom to deal with knowledge and information offering unprecedented freedom and access to the tools. This would suggest that schools no longer need to waste time on the traditional kinds of learning they deliver. Moreover, taking a radical position for those who expect it at this stage, like almost all learning outside the classroom, knowledge would be achieved without organized instruction.

We claim that the entry point for analysis and discussion of strategies to include digital technology in school practices is not the curriculum. We acknowledge that teachers need indications from the school's administration towards the use of digital technology as part of the school's resources to be used, valuing practices transformation and teaching strategies [17]. However, it is the teachers' responsibility to interpret the guidelines provided by the (probably ceaseless) school curriculum and turn them into relevant activities. This rationale has strong implications in the way schools and authorities should deal with digital technology in education and the "problem of integration of digital technology in education'.

Integration comes from the Latin word integrare, which means turning integer. Integer itself derives from in (negative) together with tangere (touching), offering the notion of 'untouched' or 'not modified'. Therefore, the very concept of integration is contradictory: on one hand, it connects to an idea of transformation and on the other hand, it links to the idea of freezing or remaining static.

However, it is widely discussed the 'integration of digital technology in the curriculum' and in fact we could imagine the same kind of discussion and analysis that Seymour [18] proposed in 1996 in an article published in The Washington Post Education Review. There, he presented the parable of 'integrating the pencil in the classroom to understand the effect in pupils learning' and suggested the irrelevance of formulating the issue of digital technology in education as a problem of 'integration'. Tom Johnson [18] addresses this issue in his blog (http://pencilintegration.blogspot. $\mathrm{com} /$ ) through an amazing dialogue.

"Here it is an exchange between Tom and his colleague, the 'Pencil Teacher' (PT) called 'Why penmanship class is failing our students':

PT: "Do you really think we need a one to one ratio of pencils to students?"

Tom: "I think it will be valuable for students. It seems like it will probably enhance learning." 
PT: "Yes, but they are already learning it in the Pencil Lab. I teach them penmanship skills and most of them have already learned to put together a document of words."

Tom: "I assure you that I won't be teaching pencil skills. Instead, we will be using pencils within the curriculum."

PT: "Tom, these kids don't know the basics. I see how they treat my pencil lab. I've had four pencils stolen despite the fact that they are bolted to the desktop. Yours will be mobile. Kids snap off erasers. I'm just worried about you, that's all."

Tom: I can't blame him for being nervous. They already use his Pencil Lab for student projects and I'm guessing he's worried that pencil-integration will eventually phase out the need for a penmanship class. Yet, honestly, he has done little to make the subject relevant. Do his students analyze the shift from an oral to a print culture? Do they look at the shifts in the world in an industrialized society and what it means for citizenship and for human identity? Do they create projects that simulate how people will use pencils in the workplace or in life? Do they write and read with pencils?"

As suggested by [4], the functions and uses of artifacts are in a constant flow and transformation that derive from the activities. Artifacts are not fixed and frozen. They do not exist outside their use by people. Artifacts are not defined externally to the practices where they are developed and where they are used. Their usefulness is not revealed analyzing the properties we identify outside the practices where they are used.

Artifacts are artifacts of practices and of participants. Therefore, they should be read and assessed in context and such context often derives from interacting with the very artifacts in question. In summary, this is our foundation to argue for the focus to be put on students' and teachers' practices with technology in school, not on processes of digital technology integration in reified objects such as the curriculum.

\section{$5 \quad$ The Need for an Evidence-Based Framework}

The fictional dialogue just presented illustrates a common oversimplification in school curricula, as well as in some research projects when dealing with the use of digital technology in the classroom. In fact, it is crucial to preserve the complexity of the situations and problems that teachers face when trying to accommodate the curriculum guidelines (that tend to be rather prescriptive) into situations in the classroom.

[19] analyzed 21 models for technology enhanced learning and found that only one developed design framework was based on empirical research. In this case, "the empirical nature of the development enabled the model to not only indicate what pertinent dimensions should be considered during contextualized technology-enhanced learning design, but also confidently provide practical guidance about how to design" (p. 991). There are clear indications of the lack of empirical-based evidence to produce guidelines towards a framework on how the use of digital technology in schools should be addressed with teachers. 
In the last section of this article, we explicit a set of principles towards a possible framework for action. An action in designing strategies to articulate research and curriculum development for the use of digital technology in school. While doing this, we stress the key claim of this article: focusing on practices will open ways to demystify the issue of integrating digital technology in the curriculum. In fact, although we recognize a social role for myths (e.g. as organizing principles for action or as part of a rationale to legitimate decisions which lack empirical evidence), we strongly take on the implications of the previous sections: innovative research agendas are needed to support the use of digital technology in education in connection to the curriculum.

\subsection{A focus on practice}

The adopted view on learning and practices recognizes that learning is an integral part of participation is practices.

- "A community of practice is an intrinsic condition for the existence of knowledge, not least because it provides the interpretive support necessary for making sense of its heritage. Thus, participation in the cultural practice in which any knowledge exists is an epistemological principle of learning. The social structure of this practice, its power relations, and its conditions for legitimacy define possibilities for learning (...)" [5] (p.98).

In order to understand the critical role of digital technology in school - as in everyday activities, we need to address practice as the focus of research. Researching on teachers' practice involves considering teachers in action using digital technology as well as other common artifacts we usually find at schools (e.g. curricula, notebooks, etc.) and at home (computers, TV sets, game platforms, mobile phones, etc.). It is crucial to consider forms of speech, types of representations and also meanings that teachers ascribe to their practice. Understanding how teachers incorporate technology in their everyday activities makes room to the claim that practice should be the focus of research efforts and opens a path to formulate evidence-based guidelines to consolidate a framework. Instead of focusing on 'integration of technology in the curriculum' we claim that the main issue is in teachers' and students' practices in school everyday, using a variety of artifacts where technology represents a rather relevant dimension.

\subsection{The unit of analysis}

Digital technologies are cultural artifacts. Individual students and teachers can no longer be viewed as detached from their cultural environment. At the same time, community can no longer be understood without the actions of individuals who use digital technology. This means that digital technology ceased to be seen simply as raw material for educational upbringing. Including the concept of activity (and activity system) [4] allows us to focus on complex interrelations between the individual subject and the community bringing forth the idea of practice. Looking at each student as 
a person who lives among a variety of activity systems where different technologies have different roles and assign different meanings to actions, - in and out of the school - it is critical to look at practices taking place within those different activity systems.

The very notion of participation emerges in teachers' and students' practices both as a process and a product. More than equated as individuals, teachers and students are participants in the social, institutional and communal world. Within this framework, the unit of analysis should incorporate simultaneously the person, the activity and the context where it evolves. The importance of defining the unit of analysis as the activity system comes from the need to specify and explicit the elements that constitute the boundaries of the analyzed practice. We not only consider the curriculum as a mediating artifact within teachers' and students' practices at school, but we also take a broader, more holistic view of what matters when researching digital technology in education.

\subsection{Research approaches to the empirical field}

Researching school practices with digital technology suggests the adoption of methodological approaches under the principle of 'fitness to purpose'. This means we should recognize the primacy of relationships between the research problem being addressed and the conceptual framework used in the analysis of empirical data collected. Preserving the dialectical relation between the empirical and theoretical fields of research is crucial to produce less bias results. We argue an eclectic approach to research regarding the type of data needed, the forms of analysis to be carried out and the methodological strategies to produce evidence and align conclusions. Following [20],

" (...) critics of research practice have argued that an adequate explanation for empirical results must convincingly show that the data occur as they do because of the processes described by the explanation, and not accidentally or coincidently (...) and to meet this requirement, the researcher cannot simply describe or identify data in terms of a framework, nor unquestioningly accept a predetermined framework, as either would be to assume, rather than to demonstrate, that an explanation derived from the framework is adequate." (p. 204)

It seems crucial that when addressing the use of digital technology in students' and teachers' practices within the frame of school curricula, researchers make decisions that convey credibility and validity to the results. These results represent a major condition for research to be considered and valued by teachers and decision makers. Research methods that seriously consider the context produced by students' and teachers' practices, and that relate results to the context of the empirical field, firmly contribute to support relevant frameworks for the use of digital technology in schooling. 


\section{Conclusion}

While addressing the issue of integrating digital technology in the curriculum, we assume a critical position regarding the discourse that maintains and concentrates efforts focused on the curriculum. We claim that the focus should be on school practices and that the quality of participation in those practices is central for the success of learning. The teacher is the key actor in creating opportunities for learning and that is why we finish this article pointing out three major under-represented issues for teachers' professional development when discussing the use of digital technology in teaching and learning.

Teacher competences: Many teachers struggle to develop their teaching competences in contexts where reform and innovation are not the dominant issues. Research on technology enhanced teacher education programs should address the way 21 st century skills are framing those training programs and how teachers or educators are prepared for that task. This means both to emphasize and value the initial and continuous teacher education programs as well as to do research on them from within.

Learning from practice: We know much less than we should about what and how teachers learn from practice. They spend most of their time doing teaching and working in the school, designing teaching and organizing activities. Reflection is necessary for effective instruction. However, reflection rarely drives instructional moves. Instead, teachers continuously observe students and continually make moment-bymoment inferences and decisions. Those would be the appropriate conditions to promote coflection [20] thus expanding the concept of reflection that traditionally teachers are encouraged to include in their practice with students, colleagues and parents. We understand far too little about how coflection helps teachers to develop from their own teaching.

Opportunities to learn: Research lacks empirical comparisons that look into different opportunities to learn when teachers use digital technology as they interpret the curriculum in the classroom. But we understand that students immersed in intentionally designed practices have greater possibility to participate and engage in activities and therefore, learn. In the extreme variety of complex contexts of schooling, the teachers become a crucial agent in identifying opportunities to learn and designing the appropriate activities. While looking at the way students use digital technology everyday - and how they engage in exploration, discovery, analysis and production teachers realize the potential in assimilating the use of those technologies in schooling. But research is needed to support and provide guidelines on the processes of naturalization of digital technologies in people practices.

\section{$7 \quad$ References}

[1] Arballo, N., Núnez, M.E. \& Tapia, B. (2019). Technological Competences: A Systematic Review of the Literature in 22 Years of Study. International Journal of Emerging Technologies in Learning (IJET), V. 14, no. 4. https://doi.org/10.3991/ijet.v14i04.9118

[2] Bernstein, B. (2000). Pedagogy, Symbolic Control and Identity: Theory Research Critique. Revised Edition. London: Taylor and Francis. 
[3] Engeström, Y. (2001). Expansive learning at work: Toward an activity theoretical reconceptualization. Journal of Education and Work, 14(1), pp. 133-156. https://doi.org/10. $\underline{1080 / 13639080123238}$

[4] Lave, J. \& Wenger, E. (1991). Situated Learning: legitimate peripheral participation. Cambridge: Cambridge University Press https://doi.org/10.1017/cbo9780511815355.003

[5] Engestrom, Y. (1999). Innovative learning in work teams: Analysing cycles of knowledge creation in practice. In Y. Engestrom, R. Miettinen, \& R.-L. Punamaki (Eds.), Perspectives on activity theory, (pp. 377-404). Cambridge: Cambridge University Press. https://doi.org 10.1017/cbo9780511812774.025

[6] Safitry, T., Mantoro, T., Ayu, M., Mayumi, I., Dewanti, R. \& Azmella, S. (2017). Teachers' Perspectives and Practices in Applying Technology to Enhance Learning in the Classroom. International Journal of Emerging Technologies in Learning (IJET), V. 10, nº3. https://doi.org/10.3991/ijet.v10i3.4356

[7] Prensky, M. (2001). Digital natives, digital immigrants. On the Horizon 9 (5). Retrieved in 21 January 2011 from http://www.marcprensky.com/writing/Prensky\%20\%20Digital\%20 Natives,\%20Digital\%20Immigrants\%20-\%20Part1.pdf. https://doi.org/10.1108/107481201 $\underline{10424843}$

[8] Prensky, M. (2004) The Emerging Online Life of the Digital Native: What they do differently because of technology and how they do it. 1-14.

[9] Battro, A. M. and Fischer, K. W. (2012), Mind, Brain, and Education in the Digital Era. Mind, Brain, and Education, 6: 49-50. https://doi.org/10.1111/j.1751-228x.2011.01137.x

[10] Gnach, A., Wiesner, E., Bertschi-Kaufmann, A. \& Perrin, D. (2007). Children's Writing Processes When Using Computers: insights based on combining analyses of product and process. Research in Comparative and International Education, Volume 2, Number 1, pp. 13- 28. https://doi.org/10.2304/rcie.2007.2.1.13

[11] Eynon, R. (2010). Supporting the "Digital Natives": what is the role of schools? In Dirckinck-Holmfeld L, Hodgson V, Jones C,de Laat M, McConnell D \& Ryberg T (Eds). Proceedings of the 7th International Conference on Networked Learning. Retrieved in 20 January from http://www.lancs.ac.uk/fss/organisations/netlc/past/nlc2010/abstracts /PDFs/Eynon.pdf

[12] Sosa, E., Salinas, J. \& Crosetti, B. (2018). Model of Incorporation of Emerging Technologies in the Classroom (MIETC)

[13] Papert, S. (1980). Mindstorms: children, computers and powerful ideas. New York: Basic Books.

[14] Flores, G., Rodríguez-Santero, J. \& Torres-Gordillo, J. (2017). Factors that explain the use of ICT in secondary-education classrooms: The role of teacher characteristics and school infrastructure. Computers in Human Behavior, Volume 68, p.441-449. https://doi.org/10. 1016/j.chb.2016.11.057

[15] Tondeur, J., van Braak, J. \& Valcke, M. (2007). Towards a typology of computer use in Primary Education. Journal of Computer Assisted Learning, 23 (3), pp. 197-206, https:// doi.org/10.1111/j.1365-2729.2006.00205.x

[16] Cabellon, E., \& Brown, P. (2017). Remixing Leadership Practices with Emerging Technologies. New directions for student leadership, 2017(153), pp. 9-20. https://doi.org/10. $1002 / \mathrm{yd} .20226$

[17] Johnson, T. (2010). http://pencilintegration.blogspot.com/. Accessed on April $29^{\text {th }} 2019$.

[18] Eisenhart, M. (1991). Conceptual frameworks for research circa 1991: ideas from a cultural anthropologist; implications for mathematics education researchers. In R. Underhill (Ed.) Proceedings of the Thirteen Annual Meeting of the North American Chapter of the International Group for the Psychology of Mathematics Education, pp. 202-220.

[19] Bower, M. \& Vlachopoulos, P. (2018). A critical analysis of technology-enhanced learning design frameworks. British Journal of Educational Technology, vol. 49, nº6, pp. 981-997. https://doi.org/10.1111/bjet.12668 
[20] Prilla, M. \& Wolf, C. (2015) Coflection - Combining Mutual Support and Facilitation in Technology Enhanced Learning. In: Conole G., Klobučar T., Rensing C., Konert J., Lavoué E. (eds) Design for Teaching and Learning in a Networked World. Lecture Notes in Computer Science, vol. 9307. Springer, Cham. https://doi.org/10.1007/978-3-319-24258$\underline{32} 21$

\section{Authors}

João Filipe Matos is a Full Professor at the Institute of Education of the University of Lisbon (IEULisboa). He holds a bachelor's (1982) and a master's (1986) degree in Mathematics, a doctorate (1991) degree, and aggregation (2000) in Education. He is the director of the Doctorate Program FCT Technology Enhanced Learning and Societal Challenges, the Doctoral course in ICT in Education, the Master's Degree Program in e-Learning and Distance Education, and the Master's Degree Program in Computer Education. He gives lectures in research methodologies in distance Education and e-Learning. He coordinates the Centre for Competence in Technology and Innovation (C2TI) of IEULisboa aimed at supporting initiatives of schools and teachers in the field of digital technologies in collaboration with the Ministry of Education. He is part of the e-Learning Lab coordination team within the framework of the e-Learning Project of the rectorate of ULisboa.

Ana Pedro has a PhD in Education - ICT in Education by University of Lisbon, Institute of Education; a Master in Psychology, Educational Psychology Specialization, by ISPA. She is a professor in Institute of Education of University of Lisbon, lecturing curricular units in the $\mathrm{PhD}$ in Education, Education Master's degrees and the Postgraduate in Technologies and Methodologies of Programming in Basic Education. She is also co-coordinator of Centro de Competência em Tecnologias e Inovação. Member of Education, Technology and Society (ETS) Research Group (Institute of Education of University of Lisbon), with the following research areas: Teachers' Professional Development and Teachers' ICT competences, Teachers' XXI Century Skills, Digital Learning, Learning Spaces and Technology Enhanced Learning. As a researcher has been member of several portuguese and international projects.

João Piedade is an assistant professor and researcher at Institute of Education of Lisbon University and member of Competence Center in Technology and Innovation. He has a Ph.D. in Education - Information and Communication Technologies in Education (2017), a master's degree in Technologies and Methodologies in Elearning (2010), and a graduation in Computer Science Engineering (2006). His experience as a teacher started in 2004 in primary and secondary schools through teaching subjects in the computer science disciplinary area. Since 2010 is involved in computer science initial teacher training programs of Institute of Education. He is author or co-author of peer-reviewed papers published in journals and in national and international conferences.

Article submitted 2019-05-15. Resubmitted 2019-07-05. Final acceptance 2019-09-08. Final version published as submitted by the authors. 